\title{
ASPECTOS MACROSCÓPICOS DE VÉRTEBRAS DE SUÍNOS FRATURADAS DURANTE O PROCESSO DE ABATE
}

\author{
(Macroscopic aspects of pig vertebrae fractured during the slaughtering process)
}

\author{
Geraldo Camilo Alberton ${ }^{1}$, Larissa Maria Moreira, Carlo Eduardo Penner Belo, Daiane \\ Güllich Donin, Peterson Triches Dornbush
}

\begin{abstract}
${ }^{1}$ Correspondência: alberton@ufpr.br
RESUMO: As fraturas em vértebras lombossacrais acontecem com frequência durante o abate de suínos, sendo desencadeadas pela forte contração muscular que ocorre nesta região em consequência da insensibilização elétrica. O objetivo deste estudo foi descrever as características das fraturas de vértebras lombossacrais provocadas pelo processo de abate e verificar se existe diferença anatômica entre os animais com e sem fratura e entre linhagens genéticas comerciais com histórico de porcentual de fraturas diferentes. Em um abatedouro localizado no estado do Paraná foram coletadas 50 peças anatômicas contendo vértebras L6 até S2 de animais de duas linhagens genéticas distintas de suínos com frequências diferentes de animais fraturados ao abate (GAF - grupo alta fratura $-n=32$ linhagem genética com $5 \%$ de fratura e GBF - grupo baixa fratura - $n=18$ - linhagem genética com $0,5 \%$ de fraturas), tanto de suínos normais $(n=28)$ como de suínos fraturados $(n=22)$. As peças foram dissecadas e submetidas à morfometria com paquímetro digital, tomando-se as medidas dos processos espinhoso, transverso e faceta articular; comprimento vertebral; espessura do corpo vertebral e o diâmetro do canal medular. As fraturas foram classificadas em transversa, oblíqua e cominutiva. O tipo de fratura predominante foi a cominutiva e a vértebra mais acometida foi a S2. Houve diferença anatômica entre os grupos GAF e GBF e entre os fraturados e não fraturados, sendo que os animais do GAF e os fraturados apresentaram vértebras maiores, mais longas e mais finas, o canal medular mais caloroso, os processos espinhosos maiores e a faceta articular menor. Conclui-se que suínos que fraturam no abate possuem vértebras lombossacrais anatomicamente mais propensas às fraturas.
\end{abstract}

Palavras-chave: eletronarcose; lombossacrais; abatedouro

ABSTRACT: Fractures in lumbosacral vertebrae occur frequently during pig slaughtering and are triggered by strong muscle contraction that occurs in this region as a result of electrical stunning. The aim of this study was to describe the fractures caracteristics in lumbosacral vertebrae triggered by slaughtering process and to determine whether there is anatomical difference between animals with and without fracture and between commercial genetic lines with history of different percentage of fractures. In a slaughterhouse located in Paraná state 50 anatomical pieces were collected containing L6 to S2 vertebraes from animals of two distint genetic lines of pigs with different frequency of fractured animals at slaughter (GAF - High fracture group - $n=32$ - bloodline with $5 \%$ of fracture and GBF $n=18$ - low fracture group - bloodline with $0.5 \%$ of fracture) from both normal pigs $(n=28)$ as fractured pigs $(n=22)$. The pieces were dissected and submitted to morphometric analysis with a digital caliper, taking measurements of the spinous processes, transverse and articular facet; vertebral length, greater and lesser thickness and diameter of the spinal canal. Fractures were classified as transverse, oblique and comminuted. The predominant type of fracture was comminuted and the most affected vertebra was the S2. There was anatomical difference between the GAF and GBF groups and among the fractured and nonfractured. The animals from the GAF and the fractured had longer and thinner vertebrae, the wider spinal canal, the largest spinous processes and lower articular facet. We conclude that swine that fracture in the slaughtering process have lumbosacral vertrebae anatomically more susceptible to fractures.

Key Words: eletrical stunning; lumbosacral; slaughterhouse

Recebido em 29/02/2016

Aprovado em 30/10/2016 


\section{INTRODUÇÃO}

No Brasil, os métodos de insensibilização para abate humanitários de animais estão regulamentados pelo Ministério da Agricultura Pecuária e Abastecimento (MAPA), de acordo com anexo da Instrução Normativa (IN) no $\mathbf{3}$, de 17 de janeiro de 2000 (Brasil, 2000). Os métodos de insensibilização aprovados por esta IN são: mecânicos (percussivo penetrativo e não penetrativo), elétrico (eletronarcose) e exposição à atmosfera controlada (dióxido de carbono). Nos frigoríficos brasileiros, o método mais empregado para abate de suínos é o da eletronarcose. Neste método, os eletrodos devem ser colocados de modo a permitir que a corrente elétrica atravesse o cérebro (Brasil, 2000).

A insensibilização elétrica pode ser realizada com a aplicação do choque apenas na cabeça do suíno ou, mediante a aplicação simultânea do choque na cabeça e na região do peito ou das costelas (sistema de 3 pontos), sendo que este último sistema promove a fibrilação do coração, evitando que os suínos retornem à consciência durante $o$ processo de sangria ou escaldagem (Wotton et al., 1992; Ludeke, et al., 2010). Entretanto, este sistema apresenta como desvantagem a promoção de intensa contração muscular, o que pode provocar fraturas vertebrais (Wotton et al., 1992; Channon et al. 2003).

São escassos os trabalhos descrevendo casos de fratura vertebrais nos suínos, sendo que os poucos artigos publicados abordam casos de fraturas ósseas em suínos que foram acidentalmente acometidos por correntes elétricas nas granjas (Bildfell et al., 1991; Alstine e Widmer, 2003).

Os objetivos deste estudo foram: descrever as características das fraturas de vértebras lombossacrais de suínos provocadas pelo processo de abate; verificar se existe diferenças anatômicas entre as vértebras de animais que apresentam e que não apresentam fratura no abate; verificar se existe diferença anatômicas entre as vértebras de animais de linhagens genéticas de suínos que apresentam histórico de fraturas no abate em diferentes percentuais.

\section{MATERIAL E MÉTODOS}

Os animais estudados foram abatidos em um matadouro-frigorífico localizado no Sul do Brasil. A insensibilização foi realizada com insensibilizador da marca Tesla, com eletrodos manuais para cabeça e peito. A amperagem, voltagem, frequência e 
tempo de exposição no Peito foi de: $0,7 \mathrm{~A}, 70 \mathrm{~V}, 110 \mathrm{~Hz}$ e 7,7 segundos e, na cabeça foi $1,8 \mathrm{~A}, \quad 251 \mathrm{~V}, 550 \mathrm{~Hz}$ e 8 segundos. Foram amostrados 50 suínos híbridos LD X LH, com peso de carcaça (PC) variando de 84 a $109 \mathrm{~kg}$, de duas linhagens genéticas diferentes, divididos em duas categorias animais: grupo de animais fraturados (GF) e grupo de animais não fraturados (GNF). As duas linhagens genéticas comparadas apresentavam

historicamente

porcentuais de fraturas bem diferentes ao abate, sendo uma com histórico de fraturas vertebrais afetando $5 \%$ dos animais, denominado Grupo de Alta Fratura - GAF; e outra linhagem genética com histórico de 0,5\% de fraturas, denominado Grupo de Baixa Fratura - GBF.

Durante o processo de abate as carcaças foram serradas ao meio, dividindo as vértebras longitudinalmente em duas partes. Foram amostrados 32 animais para o GAF, sendo 16 pertencentes ao grupo de animais não fraturados (GNF) e 16 ao grupo de animais fraturados (GF). Para o GBF foram amostrados 18 animais, sendo 12 pertencente ao GNF e seis pertencente ao GF. As peças foram retiradas das carcaças com auxílio de faca e gancho, colocadas em sacos plásticos identificados e imediatamente colocadas em caixa isotérmica com gelo. Após o término das coletas as amostras foram congeladas em freezer convencional.

No dia anterior aos exames, as amostras foram descongeladas em geladeira. A primeira etapa consistiu na dissecação da peça, com o objetivo de retirar todo tecido mole anexo às vértebras. Posteriormente foi realizada a retirada de vértebras excedentes, visando manter na peça somente as vértebras lombares L6 e L7 e sacrais S1 e S2. Com auxílio de paquímetro digital, foram tomadas a medida do processo espinhoso, processo transverso direito e esquerdo, faceta articular direita e esquerda, comprimento do corpo vertebral, espessura do corpo vertebral na porção mais estreita e na porção mais larga e diâmetro do canal medular, mensurado no meio da vértebra. Como as vértebras estavam divididas ao meio, algumas medidas foram tomadas em duplicidade, descartando-se posteriormente a medida que não retratava com fidelidade a porção anatômica avaliada. Nas peças fraturadas foi realizada descrição detalhada das fraturas.

Os resultados encontrados nas variáveis estudadas nos grupos foram submetidos à avaliação estatística pela análise de variância (ANOVA). Quando detectado efeito dos tratamentos 
seguiu-se com 0 pós-teste de comparação de Tukey/Kramer para verificar diferenças entre as médias, com segurança de $95 \%$. Após a análise do efeito da linhagem genética e da presença ou não de fratura sobre as medidas ósseas, avaliou-se, também o efeito simultâneo dos dois fatores.

\section{RESULTADOS}

O peso das carcaças variou de 84 a $109 \mathrm{Kg}$, com média de 95,91 kg, não havendo diferença entre as duas linhagens genéticas entre os animais com ou sem fratura.

Dentre os animais do GF $54 \%$ (12/22) apresentaram mais que uma vértebra fraturada. A vértebra $S 2$ foi identificada fraturada em 95\% (21/22) dos animais, a S1 em 54\% (12/22) e a L7 em 18\% (4/22). Nenhum animal apresentou fratura na L6. De acordo com o tipo de fratura, a cominutiva foi a mais frequentemente observada, em $68 \%(15 / 22)$ dos animais, seguida pela transversa em 59\% (13/22) e pela oblíqua em 54\% (12/22). Além das fraturas dos corpos vertebrais em $36 \%$ (8/22) dos animais, foram observadas fraturas no processo transverso em $22 \%$ dos casos (5/22), nos processos espinhosos em 13\% (3/22) e faceta articular em $9 \%(2 / 22)$.
A comparação das medidas das estruturas vertebrais do GBF com as do GAF (Tabela 1), e do GF com GNF (Tabela 2) revelou ausência de efeito simultâneo da linhagem genética e presença de fratura sobre as medidas ósseas. Assim sendo, as diferenças observadas sofreram influência ou da linhagem genética ou da presença ou não da fratura.

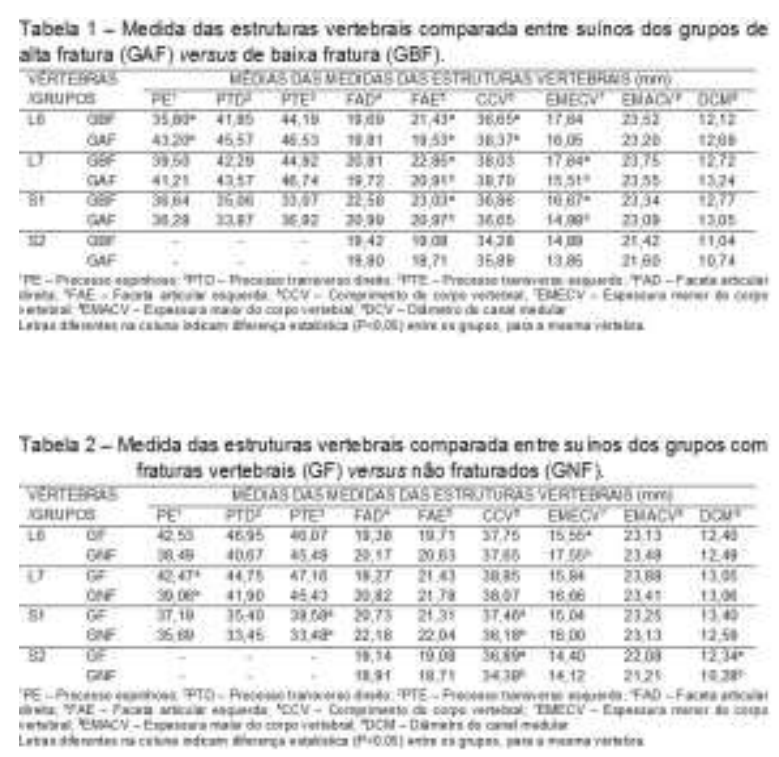

Com relação à S2, que foi a vértebra com maior frequência de fraturas, não se observou diferença anatômica entre as linhagens genéticas, mas foi observada diferença significativa entre GF e GNF. Neste sentido, o GF apresentou maior comprimento do corpo vertebral bem como maior diâmetro do canal medular (DCM) com relação ao GNF. 
No caso da S1, segunda vértebra mais frequentemente fraturada, foram observadas diferenças anatômicas entre linhagem genética e entre GF e GNF. O GF apresentou maior processo transverso esquerdo e maior comprimento do corpo vertebral em relação ao GNF. O GAF, em relação ao GBF apresentou menor faceta articular esquerda (FAE) e também menor espessura da vértebra (EMECV).

Com relação à $L 7$, foram observadas diferenças entre as linhagens e entre o GF e o GNF. O GAF teve menor faceta articular esquerda e menor medida da espessura menor da vértebra em relação ao GBF. O processo espinhoso foi maior no GF em relação ao GNF.

No caso da L6, vértebra em que não foram observadas fraturas, notou-se diferenças entre as linhagens genéticas e entre GF e GNF. O GAF apresentou processo espinhoso maior, faceta articular esquerda menor e comprimento vertebral maior em relação ao GBF. No GF, a espessura vertebral na porção menor foi menor em relação ao GNF.

\section{DISCUSSÃO}

As se comparar as vértebras entre as duas linhagens genéticas e entre os suínos com ou sem fraturas, foram observadas diferenças anatômicas em algumas estruturas vertebrais. De forma consistente, as diferenças que conferem mais fragilidade vertebral sempre foram notadas no GAF e no GF, assim sendo, em nenhuma das combinações de comparação na análise estatística o GAF e o GF tiveram medidas anatômicas que conferissem melhor resistência. Embora houvesse diferença de peso entre os animais, vale ressaltar que as diferenças anatômicas que podem conferir menor resistência às fraturas, nem sempre são menores. Como exemplo, cita-se o comprimento vertebral, que foi maior no GAF e no GF. Já a faceta articular foi menor nos animais destes grupos, o que demonstra que as medidas não foram influenciadas pelo peso dos animais. Adicionalmente, não houve diferença no peso das carcaças entre os diferentes grupos avaliados.

Os processos espinhosos e transversos servem como ancoragem de tendões e de músculos que mantém a coluna estabilizada (SISSON, 1986). Deste modo, processos transversos maiores, como foram observadas em algumas vértebras do GAF e GF possibilitam maior força de tração e efeito de alavanca nestas vértebras, o que pode contribuir para a fratura. 
As facetas articulares (FA) são estruturas que permitem movimento articular entre as vértebras (SISSON, 1986). As FAE foram menores no GAF na S1, L7 e L6, sendo que esta menor dimensão pode gerar menor possibilidade de movimento entre as vértebras. No momento da eletronarcose esta limitação de movimento pode favorecer a fratura. Além do pouco movimento conferido, o fato de da FA ser menor confere maior fragilidade, por ser um acidente ósseo pequeno e sem a possibilidade de movimentação, cedendo a forte pressão da contração muscular.

A espessura do corpo vertebral $(E V)$, que no presente estudo foi medida em dois pontos, ou seja, no ponto mais espesso (EMECV) e no mais fino (EMACV), foi menor na S1 e na L7 no GAF para a EMECV e menor para EMECV na L6 no GF. A menor espessura vertebral confere menor resistência à vértebra às fortes pressões, como no caso das contrações pela eletronarcose. Isso é comprovado pela menor espessura observada no GAF, especialmente em S1 (segunda vértebra mais frequentemente fraturada), além da ocorrência em GF, ou seja, as vértebras mais finas estavam presentes dentre as fraturadas.
O diâmetro do canal medular foi maior na S2 no GF. A vértebra com canal vertebral mais calibroso fica mais susceptível à fratura, pois a área óssea é menor e a vértebra consequentemente mais fina, não apresentando grande resistência às fortes contrações musculares.

Durante a eletronarcose utilizada no processo de abate, o choque provoca intensa contração muscular (Wotton et al., 1992), sendo que o movimento dominante é aquele comandado pela massa muscular predominante na região em questão. No caso da região lombar e sacral, uma grande massa representada pelos músculos da região transfere força para as vértebras. De acordo com o padrão de musculatura e das características anatômicas destas vértebras, a contração muscular pode gerar fraturas. Com isto, vértebras mais compridas, mais finas, com canal vertebral maior, com faceta articular menor e com processos espinhosos ou transversos maiores, teoricamente são mais susceptíveis às fraturas, fato este observado nos animais do GAF e do GF, que em algumas vértebras estudadas tiveram estas características. Adicionalmente, vale ressaltar que animais tipo carne, são mais susceptíveis às fraturas do que animais 
menos musculosos (Wotton et al., 1992), sendo que ambas as linhagens genéticas estudadas eram de animais tipo carne.

A resistência vertebral às fraturas resulta da combinação da densidade mineral óssea e da área vertebral (Yang et al, 1998). No presente estudo, embora a densidade óssea não tenha sido estudada, vale lembrar que os animais amostrados eram jovens, saudáveis e alimentados com rações comerciais que atendem as todas as necessidades nutricionais; de modo que a baixa densidade óssea não é um problema esperado para esta categoria animal.

O sistema de eletronarcose empregado neste estudo foi o de três pontos, que é mais eficiente do que o de dois pontos, mas que apresenta como desvantagem a promoção de maior número de fraturas no abate, principalmente quando o eletrodo que é aplicado no tronco é posicionado muito caudalmente (Wotton et al., 1992). Assim sendo, este estudo demonstrou que existem diferenças anatômicas nas vértebras dos suínos estudos e, que alguns animais podem estar mais susceptíveis às fraturas. Entretanto, deve-se sempre ser considerado que o fator desencadeante da fratura é a eletronarcose e que os maiores esforços na redução do percentual destas fraturas no abate devem ser aplicados na melhoria deste sistema, muito mais do que a seleção de animais com vértebras menos predispostas às fraturas.

A insensibilização elétrica é o método mais empregado nos abatedouros de suínos do Brasil. Com esta técnica, independentemente do tipo do equipamento, da regulagem do mesmo e do treinamento dos operadores, as perdas de qualidade de carne e da carcaça, bem como as fraturas ósseas são inevitáveis (Channon et al., 2003). Estas perdas podem ser reduzidas significativamente com o emprego do método de insensibilização com $\mathrm{CO}_{2}$ (Channon et al., 2003; Bertolini et al., 2006), sendo que este método já vem sendo utilizado no Brasil, com resultados muito satisfatórios na melhoria da qualidade da carne dos animais abatidos (Bertolini et al., 2006).

Não há estudos semelhantes na literatura nacional e internacional para serem comparados com os resultados dos presentes estudos. Este assunto merece ser aprofundado, uma vez que as fraturas no abate causam grandes perdas na suinocultura. 


\section{CONCLUSÃO}

As vértebras de suínos que mais fraturaram durante o processo de abate foram a S2, seguido da $S 1$ e da L7, sendo que a fratura cominutiva foi a predominante. Os suínos que fraturaram no abate e os suínos que pertenciam a linhagem genética mais susceptível às fraturas possuíam vértebras lombossacrais anatomicamente mais propensas às fraturas.

\section{NOTAS INFORMATIVAS}

O presente estudo foi aprovado pela Comissão de Ética no Uso de Animais (CEUA) da Universidade Federal do Paraná, Setor Palotina, com protocolo 41/2015.

\section{REFERÊNCIAS}

ALSTINE, W.G.; WIDMER, W.R. Lightning injury in an outdoor swine herd. Journal Veterinary Diagnostic Investigation, v. 15, p.289-291, 2003.

BERTOLINI, W.; SILVEIRA, E.T.F.; COSTA, M.R.; LUDTKE, C.B. Avaliação de diferentes híbridos suínos submetidos à insensibilização elétrica e gasosa $\left(\mathrm{CO}_{2}\right)$. Parte 3. Mensurações visuais de qualidade. Ciência e Tecnologia de Alimentos, Campinas, v. 26, n. 3, p. 555-563, 2006.
BILDFELL, R.J.; CAMAT, B.D.; LISTER, D.B. Posterior paralysis and electrocution of swine caused by accidental electric shock, Journal Veterinary Diagnostic Investigation, v. 3, p. 364-367, 1991.

BRASIL - Ministério da Agricultura, Pecuária e Abastecimento (MAPA). Secretaria de Defesa Agropecuária, Instrução Normativa no 3 , de 17 de janeiro de 2000.

CHANNON, H.A.; PAYNE, A.M \& WARNER, R.D. Effect of stun duration and current level applied during head to back and head only electrical stunning of pigs on pork quality compared with pigs stunned with $\mathrm{CO} 2$. Meat Science, v.65, p. 1325-1333. 2003.

LUDEKE， C.B.; CIOCCA， J.R.P.; DANDIN, T.; BARBALHO, P.C.; VILELA, J.A.; DALLA COSTA, O. A. Abate Humanitário de Suínos, Rio de Janeiro, WSPA, 2010. 132p.

SISSON, S. Osteologia do suíno. In: GETTY, R. Anatomia dos animais domésticos. 2 ed., Rio de Janeiro: Guanabara, 1986, v. 2, Cap.37 - 39, p. 1139-1187.

WOTTON, S.B.; ANIL, M.H.; WHITTINGTON, P.E. \& McKINSTRY, J.L. Pig Slaughtering Procedures: 
Head-to-Back Stunning. Meat Science.

v. 32, p. 245-255. 1992.

YANG, R, S.; WANG, S. S.; LIN, J.J;

LIU, T. K.; HANG, Y. S.; TSAI, K. S.

Differential effects of bone mineral content and bone area on vertebral strength in a swine model, Calcified Tissue International, v. 63 , p. 86-90, 1998. 